\title{
Cultural Relevance: A Moderator of Psychic Numbing?
}

\author{
Juliette Lennox ${ }^{1}$
}

\begin{abstract}
The term "psychic numbing" describes a paradoxical observation in human behaviour research: as the number of victims in a tragedy rises, people's emotional response to that tragedy diminishes. Correspondingly, research has demonstrated the presence of the "singularity effect," whereby our concern for a tragic event or social issue is increased when focus is narrowed onto fewer victims and more vivid victim information is made available. While these phenomena are supported by ample research, studies on the subject repeatedly overlook the impact that the cultural relevance of a particular tragic event or issue has on an individual's degree of psychic numbing. To address this caveat, the present study proposes an online survey method to gather information from a diverse sample on individuals' concern for the issue of police brutality (known to disproportionately affect Black Americans), based on both the level of victim information presented and participants' ethnocultural identification with Black American cultures. Participants will be randomly assigned to either the one-victim (vivid victim information) or multiple-victims (low victim information) condition. We predict that for less (or non) ethno-culturally identifying individuals in particular, concern for police brutality, which is measured by willingness to donate and affective response, will be significantly higher in the one-victim condition versus the multiple-victims condition. Conversely, we predict that for strongly ethnoculturally identifying individuals, the psychic numbing effect will be diminished and concern will be similarly high regardless of the number of victims shown. This alludes to the importance of cultural relevance on an individual's degree of psychic numbing.
\end{abstract}

Keywords: Psychic Numbing, Singularity Effect, Cultural Relevance, Police Brutality

\footnotetext{
${ }^{1}$ Department of Psychology, McGill University. Address all correspondence to juliette.lennox@mail.mcgill.ca.
} 
There is an adage that in regard to the large-scale loss of human life, statistics are human beings with the tears dried off. In the realm of psychology, this is referred to as "psychic numbing" - the phenomenon in which, as the number of victims in a tragedy grows, our emotional response diminishes (Slovic, Zionts, Woods, Goodman, \& Jinks, 2007). After all, when reading news of atrocity and mass death happening across the world, the majority of us who are not directly impacted are able to go about the rest of our day - or scroll through the rest of our newsfeed unaffected. The so-called "singularity effect" is part and parcel of this occurrence: our affective response and willingness to help a cause is increased when there are fewer victims and when more vivid information about the victims is made available (Kogut \& Ritov, 2005; Genevsky, Västfjall, Slovic, \& Knutson, 2013). This appeals to what Stanovich \& West (2000) call System 1 in decisionmaking: the intuitive, low-effort, and heavily emotionally-influenced system with which we make most daily decisions. It is precisely this system, and the singularity effect, which charities play on to combat psychic numbing when they encourage donors to "sponsor a child," complete with monthly pictures and updates of that specific child mailed to their doors.

Indeed, various studies have demonstrated that, owing to the fact of psychic numbing, the more people in an incident who die or are in danger, the less the extent to which people care (e.g., Fetherstonhaugh, Slovic, Johnson, \& Friedrich, 1997; Västfjall, Slovic, Mayorga, \& Peters, 2014). In perhaps the most widescale study of this phenomenon to date, Bhatia, Walasek, Slovic et al. (2020) found that in over 100,000 mentions of death found across news articles and social media posts, the language which authors used tended to exhibit significantly less negative affect and arousal when describing large numbers of deaths. Elsewhere, researchers found that people's affective responses and willingness to donate to a cause decreased significantly when they were shown images of two victims as opposed to one (Västfjäll et al., 2014). Psychic numbing and the concomitant singularity effect, therefore, are seemingly an innate byproduct of the mind's affective and decision-making processes. 
There is, however, a caveat to the literature on psychic numbing that has yet to be explored. The conclusion of Bhatia et al.'s study, like others of its kind, ignores the salient fact that for most Western studies, events involving a large number of deaths typically occur in culturallyremoved contexts. North Americans rarely spend time grieving over wars or genocides in the Middle East. By contrast, the emotional valence of large-scale tragedies occurring on American soil, such as the September 11 attacks, are still felt widely by Westerners today. Additionally, in interviews conducted with Armenian-American high school students in L.A. after the 1988 earthquake in Armenia, measures of emotional valence and drive to help were found to be extremely high, despite the large death toll and physical distance from the site (Yacoubian \& Hacker, 1989). This suggests that cultural distance (beyond physical distance) may be a mediating factor in psychic numbing, affecting people's emotional reaction to large-scale tragedies and their subsequent desire to contribute to associated causes. In other words, if a tragedy involves many people of a certain culture, individuals strongly identifying with that in-group (i.e., cultural group) should show resistance to psychic numbing, rendering the singularity effect irrelevant. One could presume that their emotionally-driven System 1 of decision-making will be supplementarily activated by in-group moral emotions such as empathy, guilt, and if applicable, anger towards any outgroup (i.e., cultural group to which they do not belong). Conversely, if individuals are culturally removed from a tragedy, singularity effects should be needed to bridge the gap and aid that individual's ability to empathize. To our knowledge, no studies to date have measured cultural relevance as a potential moderator of psychic numbing.

To test the effects of cultural relevance on psychic numbing and the subsequent singularity effect, we propose the use of a survey method to gather data from a large number of diverse individuals. The surveys will measure participants' willingness to donate a portion of the study compensation to combat the current endemic issue of police brutality, as well as their affective response to the issue, based on the number of victims and vividness of victim 
information presented (either multiple victims/low victim information or one victim/vivid victim information). Since police brutality is an issue known to disproportionately affect Black Americans, we will measure participants' identification with and views towards Black American cultures (i.e., their degree of ethnocultural identification with Black American cultures) as a proxy for the issue's cultural relevance.

We hypothesize that both the level of victim information shown and the cultural relevance of police brutality will have a significant effect on the degree of psychic numbing seen in participants. Specifically, we hypothesize that donation amounts and affective responses will increase proportionally with participants' degree of ethnocultural identification, with a significantly steeper increase for the multiple-victims/low victim information condition. That is, we predict that for less (or non-) ethnoculturally identifying individuals, donation amounts and affective responses will be significantly higher given the detailed description of one individual victim versus the depiction of multiple victims. For strongly ethno-culturally affected individuals, we predict that the psychic numbing effect will be negated, and their level of concern will not be significantly affected by the level of victim information (or condition they are assigned to).

\section{Methods}

Defining "Black American" culture

Defining culture, especially in regard to a group so diverse in origin and experience as Black Americans, is a complex task (see Hernandez \& MurrayJohnson, 2015; Johnson, 2008; Landry, 2018). There is not one uniform "Black American" culture. Hence, for the purpose of this study, we will conceptualize Black American culture to include the experiences, beliefs and customs of the different subgroups of Black people living in America. This might include that of either a) Americanborn Black people with historical roots in America (i.e., those whose ancestors were brought to America from Africa involuntarily in the transatlantic slave trade), or b) more recent, voluntary Black immigrants to America from Africa as 
well as other areas (e.g., the Caribbean, Oceania, Asia, or Europe) (Landry, 2018).

Our decision to include all of these groups lies in that they are similarly affected by the pervading historical categorization of "Black" in America based solely on race (i.e., skin colour), and correspondingly are all disproportionately affected by police brutality (Johnson, 2008). Participants will be asked to refer to the specific subculture with which they are most acquainted when answering the survey.

\section{Participants}

This study aims to recruit 200 adults residing in the United States and Canada, aged 18 years and older. Sampling quotas will be used to ensure adequate diversity in race/ethnicity (with the goal of obtaining 100 Blackidentifying and 100 non-Black-identifying participants).

\section{Procedure}

Surveys will be administered and participants will be recruited using the online survey software Qualtrics. The study will be portrayed as an investigation into the effects of various social issues on different demographics.
Participants will first give their informed consent (with the consent form highlighting anonymity of data, as well as an explicit trigger warning on the depiction of content relating to police brutality) and answer demographic questions regarding their race and socioeconomic status. They will then complete a questionnaire regarding their ethnocultural identification with/views towards Black American culture in any of its various forms. Finally, they will be given information on the epidemic of police brutality in North America. One group will be shown ten purported victims of police brutality for which the only individually-identifying information available is their names. Another group will be shown a single purported victim with ample (vivid) individuallyidentifying information (i.e., their name, their age, a picture of them, and a testimonial of their character). In order to account for participants having already encountered and processed the stories of real-world victims of police brutality, true victim information will not be used in either condition. To maintain external validity, the testimonial in the singlevictim condition will be loosely based on 
that of a real victim, with identifying details (i.e., name, age, occupation) changed. After viewing the section on police brutality, participants will be asked to rate their concern over this issue, and their willingness to donate a portion of their study compensation to raise awareness and aid victims' families. Finally, participants will be given a debrief on the true nature of the study, outlining the gap in the literature which the work intends to address.

\section{Additional procedures for Black participants}

It is important to note that the content of the survey has the potential to be particularly distressing to Black participants. To address this concern, a live talk therapy session with a Black counsellor will be made available so as to help mitigate any trauma or negative emotion experienced during the study. Furthermore, additional monetary compensation will be provided to Black participants once the study is over, in an effort to recompense for any extra harm suffered due to the subject matter.

\section{Measures}

Ethnocultural identification (cultural relevance of police brutality)

Participants' identification with and views towards Black American culture (in whichever form they are best acquainted with) will be measured using Duckitt's (2008) validated measures of Ethnocultural Group Identification (see Appendix), adapted to refer specifically to the target cultures described in the above section, Defining "Black American" culture. Ethnocultural identification can be defined as an individual's level of involvement with, attachment to, and generalized attitude towards a particular culture (Duckitt, 2008). The assumption here is that this measure will capture the effects of culture beyond the categorical measure of race; it is true, for example, that some Black Americans (in particular, those with higher socioeconomic status) associate more with White culture (Harris \& Khanna, 2010), and so it might similarly be assumed that some non-Black individuals (for example, those with lower socioeconomic status) are more deeply immersed in certain aspects of Black American culture. The scale will comprise of a combined measure of 
Ethnocultural Involvement (e.g., "I would teach my children to respect and enjoy this culture and ethnic heritage"), Ethnocultural Attachment (e.g., "I am a person who considers the people of this ethnic/cultural group important"), and Generalized Group Attitude (e.g., "sometimes I think this country would be better off without so many [Black] people"). All questions will be answered on a 7-point Likert-type scale, with overall low scores indicating low identification with/reverence for Black American culture and vice-versa (reversed items scored accordingly).

\section{Racial Identity}

Participants' race will be indicated via an inclusive variety of categorical options. Participants will be asked to signify which of these race(s) they identify with. For quota purposes, these will be translated to the binary measure of Black-identifying and non Blackidentifying (all other options).

\section{Concern over police brutality}

Participants' overall concern for the target issue will be measured by (1) their self-reported affective response after reading about the issue and victim(s) (i.e., how distressed, from 1 (not at all) to 5 (very much), they feel over the issue of police brutality) and (2) how much, if any, of their study compensation they are willing to donate to the cause. Affective response and donation amounts are two common, validated proxies of psychic numbing (e.g., Kogut \& Ritov, 2005; Västfjall et al., 2014).

\section{Socioeconomic status (SES)}

Participants' socioeconomic status (a control variable) will be measured using the continuous variable of annual household income.

\section{Data Analysis}

We will use ANCOVA to predict participants' concern for (i.e., affective response and donations to) police brutality based on the cultural relevance of police brutality to the participant. This relevance is based on the degree of ethnocultural identification with Black American cultures, and is moderated by whether one victim (with vivid information) or multiple victims (with low information) are shown. Annual household income will be included as a covariate to control for SES, as one of our dependent variables is monetary. In line 
with the literature, we expect to see a significant main effect of condition (level of victim information provided) on both variables measuring concern for police brutality. We also expect to see a significant main effect of cultural relevance on concern.

In addition to these main effects, we expect to see a significant interaction effect between cultural relevance and condition (see Figure 1). That is, when ethnocultural identification with Black American cultures is high, we predict that the number of victims or vividness of victim information shown will not have a significant effect on donation amount or affective response to police brutality (i.e., concern for the issue will be similarly high between the one-victim/high vividness and multiple-victims/low vividness conditions). Conversely, when ethnocultural identification is low, we predict that concern will be significantly greater given the one-victim/high vividness condition as opposed to the multiple-victims/low vividness condition. 


\section{Hypothesized Effect of Ethnocultural Identification with Black American Cultures on Donation Amount/Affective Response to Police Brutality}

One-victim (high vividness)

Multiple-victims (low vividness)

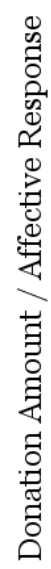

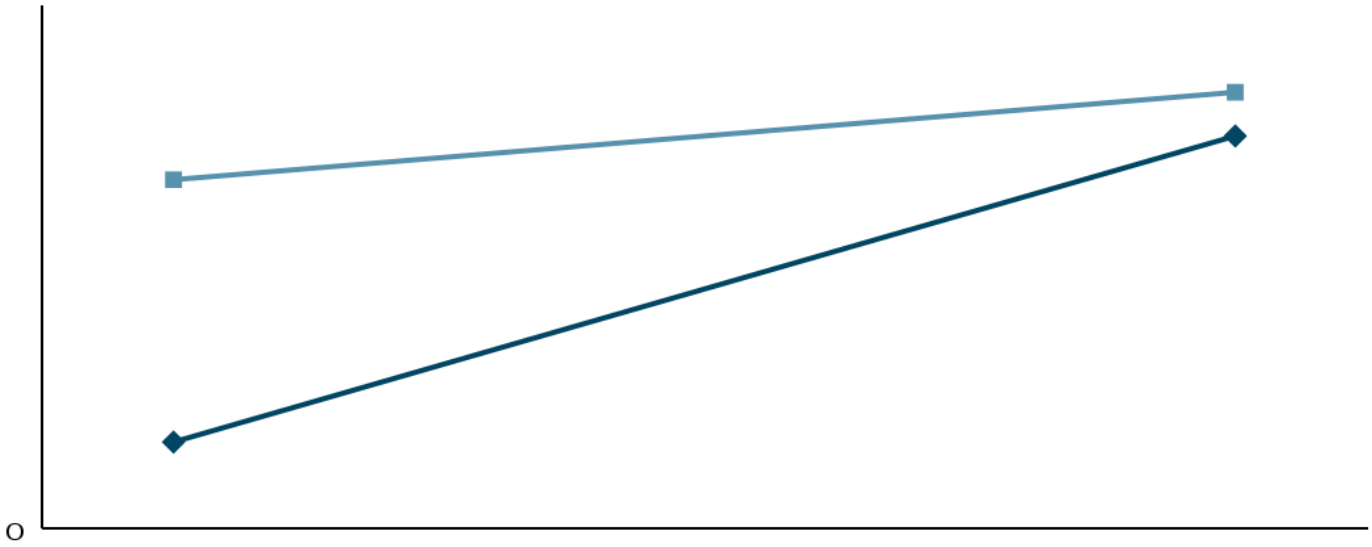

Degree of Ethnocultural Identification

Figure 1: Hypothesized effect of ethnocultural identification with Black American cultures (i.e., cultural relevance of police brutality) on donation amount or affective response to (i.e., concern over) police brutality, depending on whether participants are shown one victim with vivid victim information, or multiple victims with minimal victim information. Precise numbers will depend on the exact variable being measured. 


\section{Discussion}

To reiterate, we hypothesize in this experiment that both the level of victim information shown to participants and the cultural relevance of police brutality will have a significant effect on the degree of psychic numbing (i.e., concern) seen with respect to the issue. In particular, we hypothesize an important interaction between these two predictors. That is, for participants to whom the issue of police brutality is of high cultural relevance, we predict that concern (donation amounts and affective response) will be similarly high regardless of the level of victim information provided. Conversely, if the issue is of low cultural relevance to the participant, we predict that being shown one victim with vivid victim information would result in much higher affect and donation amounts than being shown multiple victims with less vivid victim information.

Given the expected pattern of results, we might then consider cultural relevance as a potential moderator of psychic numbing, with implications for the salience of the concurrent singularity effect (see Figure 2). This would make sense given that high cultural relevance could be seen as serving the same function as identifiable victim information in diminishing psychic numbing, in that both factors likely raise the level of compassion an individual might feel towards the victims at hand. Whereas the singularity effect is elicited by the explicit portrayal of a single victim, individuals who feel culturally close to a victim likely experience this degree of empathy regardless; after all, it could have been them in their place. In fact, people may experience a form of survivor's guilt regarding culturally significant tragedies (e.g., Yacoubian \& Hacker, 1989).

If the expected results are not found (if cultural relevance does not have any effect on psychic numbing), it could indicate a problem with the study's methods, or simply a problem with the theory itself. Perhaps, contrary to our inferences, the influence of cultural relevance is minimal when tested directly against psychic numbing. This would be a surprising, but not an impossible outcome. Alternatively, it could mean the design of this study was not able to adequately capture the effects of cultural relevance on psychic numbing. Possible 
causes of such limitations will be discussed below.

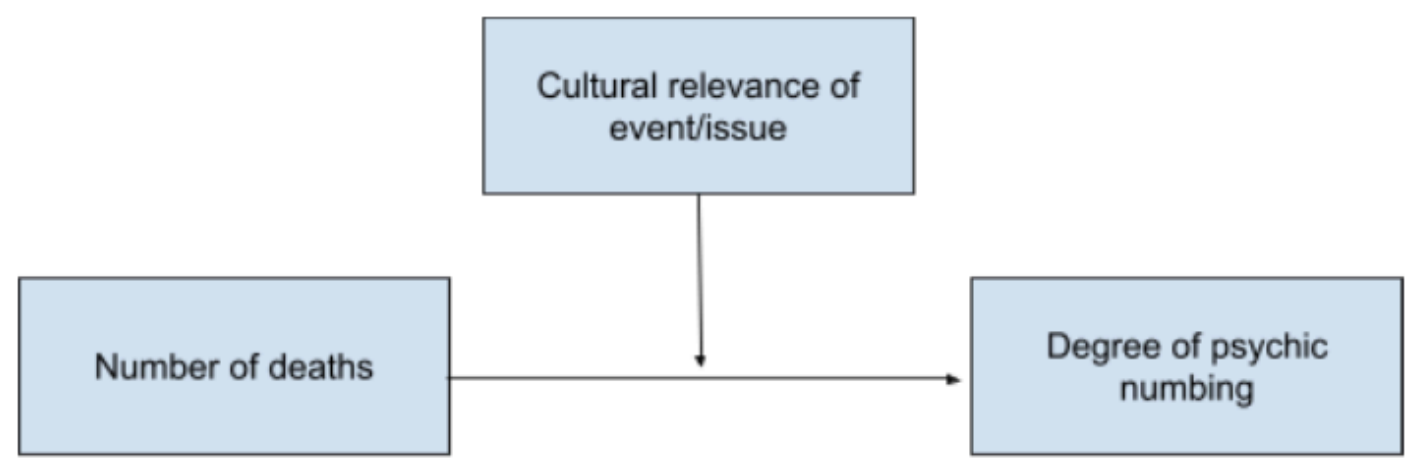

Figure 2: Theoretical model of cultural relevance as a moderator of psychic numbing (and concurrent salience of the singularity effect). 


\section{Limitations and Future Directions}

As always, there are potential limitations to this study design which should be taken into account. First, it is possible that the completion of the ethnocultural identity questionnaire could affect participants' answers to subsequent questions regarding police brutality, either through priming or by hinting towards the study's purpose. These order effects might be negated by counterbalancing the order of these two components, time-separating the two parts, or embedding them into a larger set of questionnaires. Second, participants' answers might be influenced by demand effects of what is "morally correct," especially since the study examines helping behavior. While it is not possible to eliminate these effects entirely, they are minimized by emphasizing the anonymity of responses, as well as by the online (i.e., more private) nature of the study. In general, self-report measures are not entirely reliable. Therefore, future investigations might benefit from using in-lab experimental (e.g., physiological) measures of psychic numbing, in addition to self-report measures. Finally, it is notable that this study only seeks to examine responses to one culturally specific issue. Looking forward, one might imagine a more ambitious design wherein multiple issues, relevant to multiple cultures, are tested. This would increase the reliability of the results as well as the diversity of knowledge to be gained from them.

Furthermore, it is important to once again acknowledge the complexity that lies in studying culture, particularly when it is heavily intertwined with ethnicity or race. In order to be inclusionary with the way in which this study defined Black American culture, we constructed a very broad definition of what "Black American" might mean. While this allows us to investigate whether a general relationship exists between psychic numbing and ethnocultural identification in regard to an umbrella of relevant groups, we do not intend to insinuate that all of these groups and their members are necessarily uniform in their outlook. For example, while both domestic-born and foreignborn Black Americans are likely to suffer equally from police brutality (Johnson, 2008), certain instances show that the latter group, being further removed from 
the other's collective historical trauma and likely otherwise concerned with their home country's issues, might be, to an extent, less concerned with police brutality (Johnson, 2008). Deeper analysis from a sociological lens might look to further parse apart the levels of psychic numbing seen in relation to these different groups. Moreover, Critical Race Theory reminds us to account for the fact that people's outlooks are unavoidably "gendered, classed, and racialized" (Salter \& Haugen, 2017, p. 128). When interpreting our results, we must be careful to acknowledge the implicit or explicit racism which is inextricably connected to people's relationships with Black issues and culture. Further work on the current research example, as well as examples involving other cultures, will allow us to parse apart cultural identity from potential confounds such as this.

If this study's predictions hold, a new avenue of research into psychic numbing could be opened. A logical next step might entail investigation into the particular factors by which cultural relevance influences the degree of psychic numbing experienced. For example, one might compare the specific cultural- relevance related variables of increased empathy, fear, anger towards an implicated out-group, or increased knowledge and tangibility of the issue present at hand. Additionally, it could be of interest to examine whether psychic numbing levels can reveal solidarity between certain cultural groups. In the case of the present study, this might be seen with non-Black ethnic minority groups or other marginalized groups such as the LGBTQ+ community, who might feel that they, to a certain extent, encounter similar forms of oppression to the Black community. Importantly, the results of the present work could indicate cultural relevance as a major caveat to the literature on psychic numbing, holding the potential to account for some of the effects previously attributed to psychic numbing. If not used as a topic of investigation in its own right, researchers may want to keep cultural relevance in mind as a potential confound when designing future studies on singularity effects and psychic numbing. 


\section{References}

Bhatia, S., Walasek, L., Slovic, P., \& Kunreuther, H. (2020). The more who die, the less we care: Evidence from natural language analysis of online news articles and social media posts. Risk Analysis.

Brown, R., Condor, S., Matthews, A., Wade, G., \& Williams, J. (1986). Explaining intergroup differentiation in an industrial organization. Journal of Occupational Psychology, 59, 273-286.

Duckitt, J. (2008). Ethnocultural group identification and attitudes to ethnic outgroups.

Zheng, I. G., Leung, K., \& Adair, J. G. (Eds.), Perspectives and progress in contemporary cross-cultural psychology: Proceedings from the 17th International Congress of the International Association for Cross-Cultural Psychology. https://scholarworks.gvsu.edu/iaccp_papers/16/

Fetherstonhaugh, D., Slovic, P., Johnson, S., \& Friedrich, J. (1997). Insensitivity to the value of human life: A study of psychophysical numbing. Journal of Risk and uncertainty, 14(3), 283-300.

Genevsky, A., Västfjall, D., Slovic, P., \& Knutson, B. (2013). Neural underpinnings of the identifiable victim effect: Affect shifts preferences for giving. Journal of Neuroscience, 33(43), 17188-17196.

Harris, C. A., \& Khanna, N. (2010). Black is, Black Ain't: Biracials, middle-class blacks, and the Social Construction of Blackness. Sociological Spectrum, 30(6), 639-670. https://doi.org/10.1080/02732173.2010.510057

Hernandez, K. A. C., \& Murray-Johnson, K. K. (2015). Towards a different construction of blackness: Black immigrant scholars on racial identity development in the United States. International Journal of Multicultural Education, 17(2), 53-72.

Johnson, V. M. S (2008). What, then, is the African American? African and AfroCaribbean identities in Black America. Journal of American Ethnic History, 28(1), 77-103. Kogut, T., \& Ritov, I. (2005). The singularity effect of identified victims in separate and joint evaluations. Organizational behavior and human decision processes, 97(2), 106116.

Landry, A. (2018). Black is black is black?: African immigrant acculturation in Chimamanda Ngozi Adichie's Americanah and Yaa Gyasi's Homegoing. MELUS: Multi-Ethnic Literature of the United States, 43(4), 127-147.

Salter, P. S., \& Haugen, A. D. (2017). Critical race studies in psychology. In The Palgrave handbook of critical social psychology (pp. 123-145). Palgrave Macmillan, London. Slovic, P., Zionts, D., Woods, A. K., Goodman, R., \& Jinks, D. (2007). Psychic Numbing and Mass Atrocity. Judgment and Decision Making, 2, 79-95.

Stanovich, K. E., \& West, R. F. (2000). Individual differences in reasoning: Implications 
for the rationality debate? Behavioral and Brain Sciences, 23, 645-726.

Västfjall, D., Slovic, P., Mayorga, M., \& Peters, E. (2014). Compassion fade: Affect and charity are greatest for a single child in need. PloS one, 9(6), e100115.

Yacoubian, V. V., \& Hacker, F. J. (1989). Reactions to disaster at a distance: The first week after the earthquake in Soviet Armenia. Bulletin of the Menninger Clinic, 53(4), 331. 


\section{Appendix}

\section{Measures of Ethnocultural Identification (adapted from Duckitt, 2008) Ethnocultural Involvement}

1. I have a good knowledge of the customs and rituals of this culture or ethnic group.

2. I avoid functions involving customs or rituals typical of this culture or ethnic group.

3. I would NOT care if children of mine never learned anything about this culture or ethnic group.

4. I am NOT interested in learning about this culture or ethnic group.

5. I enjoy attending functions involving customs and rituals of this culture or ethnic group.

6. I enjoy the sense of humour that people of this culture or ethnic group have.

7. I prefer NOT to eat the food typical of this culture or ethnic group.

8. I would teach my children to respect and enjoy this culture and ethnic heritage.

Ethnocultural Attachment (Brown, Condor, Matthews, Wade, \& Williams, 1986)

1. I am a person who is, or would be, glad to belong to this ethnic/cultural group.

2. I am a person who sees myself as belonging to this ethnic/cultural group.

3. I am a person who would make excuses for belonging to this ethnic/cultural group.

4. I am a person who would try to hide belonging to this ethnic/cultural group.

5. I am a person who feels strong ties with this ethnic/cultural group.

6. I am a person who feels held back by this ethnic/cultural group.

7. I am a person who would be annoyed to say that I am a member of this ethnic/cultural group.

8. I am a person who considers the people of this ethnic/cultural group important.

9. I am a person who identifies with this ethnic/cultural group.

10. I am a person who criticizes this ethnic/cultural group.

\section{Generalized Group Attitude Scale}

1. It really upsets me to hear anyone say anything negative about the (target group) people.

2. The (target group) people have some very bad characteristics.

3. I have a very positive attitude to the (target group) people.

4. There is little to admire about the (target group) people.

5. The (target group) people have done a great deal to make this country successful.

6. Sometimes I think this country would be better off without so many (target group) people.

7. The (target group) people should get much more recognition for what they have done 


\section{Cultural Relevance}

for this country.

8. I can understand people having a negative attitude to the (target group) people. 